\title{
Sentido, educação e memória: a Educação de Jovens e Adultos em Pouso Alegre-MG
}

\author{
Marilda de Castro Laraia \\ Universidade do Vale do Sapucaí (UNIVAS), Pouso Alegre, Minas Gerais, Brasil \\ marildalaraia@gmail.com \\ http://orcid.org/0000-0001-5222-5920
}

DOI: http://dx.doi.org/10.21165/el.v47i3.2003

\begin{abstract}
Resumo
Neste artigo, propõe-se analisar o processo de construção da Educação de Jovens e Adultos (EJA) e suas diferentes Formações Discursivas (FD) em sua prática pedagógica na cidade de Pouso Alegre-MG. Para isso, observa-se a memória e o sentido que essas FD'S possuem na construção do processo de identificação dos educadores. O corpus de análise foi composto de documentos oficiais (leis) e entrevistas orais. No que diz respeito à discussão teórica e metodológica, ela está filiada à área de língua e ensino dentro da Análise de Discurso. Assim, a linguagem é pensada neste trabalho sempre articulada às práticas sociais e históricas, produzindo sentidos que possam oportunizar uma maior compreensão da EJA e dos sujeitos envolvidos neste processo de ensino aprendizagem.
\end{abstract}

Palavras-chave: EJA; memória; linguagem; Análise de Discurso.

Sens, éducation et mémoire: l'éducation des jeunes et des adultes à Pouso AlegreMG

\section{Résumé}

Dans cet article, on se propose d'analyser le processus de construction de l'Education des Jeunes et des Adultes (EJA) et ses différentes formations discursives dans sa pratique pédagogique dans la ville de Pouso Alegre-MG. Pour cela, on observe la mémoire et le sens qui les FD's ont dans la construction du processus d'identification des enseignents. Le corpus d'analyse a été composé de documents officiels (lois) et des entretiens oraux. La discussion méthodologique et théorique s'inscrit à l'Analyse du Discours. Ainsi, dans cette recherche, on comprend le langage articulée aux pratiques sociales et historiques et comme source des significations qui peuvent permett de mieux comprendre l'EJA et les sujets impliqués dans ce processus d'enseignement et apprentissage.

Mots clés: EJA; mémoire; langage; Analyse du Discours.

\section{Apresentação}

A Análise de Discurso é de fundamental importância para esta pesquisa, pois seus dispositivos teórico-analíticos oportunizam uma reflexão sobre o poder da ideologia dominante que se faz presente na EJA e nos discursos dos sujeitos sociais que a compõem. Esses discursos demonstram diferentes sentidos relacionados à busca do saber ensinar, saber escrever e saber ler, buscando a esperança de uma vida melhor, conectados às exigências de um país neoliberal. Neste artigo, buscamos articular e interpretar como estes sentidos se constituem para o sujeito professor na Educação de Jovens e Adultos. 
Para isso, consideramos que os sentidos estão sempre em funcionamento e nunca soltos, como destaca Orlandi (2005, p. 10). "Ao atribuir sentidos, os sujeitos, ao entrar em contato com o objeto simbólico, são instados a interpretar e, ao interpretar, retomam os sentidos que sempre estiveram lá". Ao trabalhar com a Análise de Discurso, focamos o que chamamos de memória discursiva ou interdiscurso, trazendo para a discussão neste estudo a ideologia, pois como nos destaca Orlandi (1997) o estudo da linguagem oral não pode estar separado da sociedade que a produziu. Os processos que entram em jogo na constituição da linguagem são processos histórico-sociais, em que não consideramos a sociedade como um dado nem a linguagem como produto. Sabemos que as condições de produção dos discursos estão relacionadas às relações de poder e do lugar ocupado pelo sujeito do discurso e por seus interlocutores. É neste contexto que os discursos envolvem os sujeitos, a situação e sua memória discursiva, numa relação de diálogo com a realidade que os circunda e com a história.

A memória discursiva nesse trabalho é entendida como interdiscurso, pois "alguma coisa fala antes, em outro lugar e independente" (PÊCHEUX, 1991, p. 142). A memória aqui faz parte de um processo histórico, em que há uma linguagem em funcionamento que se apropria da memória e manifesta-se de formas e discursos diferenciados.

Com o escopo de compreender as formações discursivas nas quais os sujeitos se inscrevem, a metodologia aplicada foi a realização de entrevistas por meio da técnica da história oral, que busca as histórias de vida de cada narrador, possibilitando entender as diferentes memórias, discursos e sentidos sobre o ensino-aprendizagem e a constituição do processo de identificação dos sujeitos sociais nele envolvidos.

Importante ressaltar que é a partir desse corpus documental composto de entrevistas que se realizou a análise de discurso desses sujeitos para este trabalho, considerando que toda a memória interpretada pelos narradores e falada a esta pesquisadora são uma construção ideológica da relação imaginária entre sujeito e mundo.

Com os discursos falados pelos narradores, é possível compreender aspectos que não poderiam ser entendidos de outra forma, principalmente quando se refere à história de grupos excluídos dessa sociedade, pois, conforme se vê:

O uso do testemunho oral possibilita à história oral esclarecer trajetórias individuais, eventos ou processos que às vezes não têm como ser entendidos ou elucidados de outra forma: são depoimentos de analfabetos, rebeldes, mulheres, crianças, miseráveis, prisioneiros, loucos [...] São histórias de movimentos sociais populares, de lutas cotidianas encobertas ou esquecidas, de versões menosprezadas; essa característica permitiu inclusive que uma vertente da história oral se tenha constituído ligada à história dos excluídos. (AMADO, 2002, p. 16).

As entrevistas orais foram aplicadas a três professores do Centro Municipal de EJA, que ministram aulas no Centro Integrado de Ensino Municipal, onde funciona o ensino de jovens e adultos no período noturno. Tais entrevistas foram realizadas com a finalidade de verificar como esses sujeitos sociais compreendem os diferentes discursos e sentidos que o ensino da EJA possui no processo de formação de discurso do sujeito. 


\section{O sujeito professor e a EJA}

Na Análise de Discurso, "o processo de identificação é compreendido como movimento do sujeito na relação que estabelece com a posição - sujeito, como com a forma-sujeito da formação discursiva em que se inscreve" (CAZARIN, 2004, p. 129).

Pode-se observar, então, que o sujeito se identifica diante de suas formações discursivas, isto é, o sujeito professor tem a sua formação discursiva diferente da formação discursiva de seus alunos. Quando se analisam os recortes retirados do discurso do professor, busca-se compreender como o processo de identificação desse sujeito professor acontece.

Para Orlandi (2011, p. 8), os processos de identificação,

Por sua vez, engendram tensões, contradições, tanto da imagem que ele faz de si mesmo como em sua ação no seio da sociedade. [...]. Podemos ser [...], por exemplo, simultaneamente operária, mãe, militante socialista, cristã, fumante etc. Há aí algumas misturas, mas, como analista de discurso [...] afirmando que dos processos de identificação dos sujeitos individualizados, portanto dos indivíduos, com as diferentes formações discursivas, resultam posições sujeitos distintas, que, como sabemos, podem ter entre si uma infinidade de natureza de relações.

Para Orlandi (2005), a formação discursiva é básica na AD. Ela permite a compreensão do processo de produção dos sentidos, ou, em outras palavras, a sua relação com a ideologia. Essa noção dá ao analista a possibilidade de estabelecer regularidades no funcionamento do discurso. Norteado por este aporte teórico analítico, procurou-se compreender como se realiza o processo de formação dos sentidos dos sujeitos professores da EJA.

Foi realizada uma entrevista oral com um educador da EJA e transformada em documento escrito. Para tal, vejamos o discurso do professor D, de 44 anos, que ministra a disciplina de matemática há oito anos na EJA do Ensino Fundamental:

Pesquisadora: Professor, como o senhor vê o aluno da EJA? Como cidadão? O senhor o vê?

Professor: O aluno de EJA é assim, um aluno especial, né? Ele contribui muito para a sociedade, porque trabalha, tem aquele interesse de aprender, ele quer se desenvolver também, então antigamente tinha um pessoal que era bem mais velho, né? Então, vinham aqui por causa do convívio, queria só aprender mesmo só pro dia a dia. Mas agora a gente sente que estes alunos de hoje, além de querer aprender para a vida deles, eles querem também uma profissão. Eles querem usar essa aprendizagem no trabalho deles.

Diante dessa resposta do professor D, é possível separar alguns recortes de sua fala para análise. Um deles chama a atenção, quando o professor afirma: "O aluno de EJA é assim, um aluno especial, né? Ele contribui muito para a sociedade, porque trabalha".

O entrevistado, aqui sujeito professor, destaca que o aluno da EJA é um "aluno especial”, por ele já contribuir para a sociedade com sua mão de obra. A noção de formação dos jovens e adultos para atender ao sistema capitalista e à mão de obra necessária para os empregadores leva o aluno da EJA a ser considerado "especial", ou seja, é visto como aquele que deve ter aptidões específicas para usá-las em seu trabalho e, em sua maioria, direcionadas a um único fazer, algo automático, porém, segundo o 
professor, há uma busca pelo saber almejando uma profissão mais qualificada, consequentemente, uma melhor condição social. Podemos, aqui, rememorar a cena do filme de Charlie Chaplin, intitulado Tempos Modernos, em que os homens precisam apenas apertar e girar botões. Destaca-se, pois, na formação discursiva desse professor, uma memória já cristalizada, na qual já se disse que o sujeito, para colaborar com a sociedade, deve produzir, isto é, deve trabalhar e atender às necessidades do sistema.

A noção de formação discursiva tomada de empréstimo a Michel Foucault começa a fazer explodir a noção de máquina estrutural fechada: uma formação discursiva não é um espaço estrutural fechado, pois é constitutivamente "invadida" por elementos que vêm de outro lugar (isto é, de outras formações discursivas) (PÊCHEUX, 1990).

É sob essa perspectiva que se identificou a figura do professor enquanto sujeito, capaz de intervir negativa ou positivamente na realidade do estudante, podendo, desse modo, permitir ao estudante uma aprendizagem ineficiente ou significativa, com vistas a uma possível transformação.

Para Orlandi (2001), uma posição-sujeito não é uma realidade física, mas um objeto imaginário, representando, no processo discursivo, os lugares ocupados pelos sujeitos na estrutura de uma formação social.

Sob esse aporte, pode-se compreender a intenção do professor, ao se propor a ensinar esses sujeitos alunos da EJA, de dar condições para que o sujeito aluno venha a ocupar o seu lugar dentro da sociedade, fazendo com que sua posição sujeito saia do imaginário e passe para o real, que é ser um cidadão letrado para o mundo do trabalho.

Segundo Gadotti (1979), a Educação de Jovens e Adultos deve ser sempre uma educação multicultural, uma educação que desenvolva o conhecimento e a integração na diversidade cultural.

Por outro lado, para Pinheiro e Silva (2010), os estudantes da EJA são parte integrante de uma realidade carente de cultura letrada, em meio a uma sociedade cujos conhecimentos se tornam cada vez mais específicos para atender às exigências do mercado. Os autores enxergam, no processo "tardio" de alfabetização, uma alternativa para o alcance dos objetivos traçados pela sociedade do trabalho, vislumbrando, desse modo, uma possível mobilidade social.

No entanto, as ações que movem a EJA vêm se configurando como uma prática emergencial de alfabetização, na qual a metodologia abordada por um grande número de escolas consiste em voltar suas ações unicamente para a alfabetização com base na decodificação, constituindo uma conduta pedagógica mecânica e descontextualizada, em detrimento às propostas com base no letramento dos sujeitos, contribuindo, desse modo, para a formação de trabalhadores cuja aptidão se limita a exercer habilidades pertinentes ao seu ofício, atendendo apenas aos interesses capitalistas de um país neoliberal. Sob esse viés, poucos realizam uma reflexão sobre as causas da realidade na qual estão inseridos, reproduzindo muitas vezes discursos fundadores, do qual excluem o passado do presente e não planejam um futuro diferente.

Continuando as análises, observa-se os recortes a seguir da fala do professor D: "antigamente tinha um pessoal que era bem mais velho, né? Então, vinham aqui por causa do convívio, queria só aprender mesmo só pro dia a dia”. Essa resposta do professor faz ressurgirem as respostas ouvidas por alguns alunos da EJA, em uma pesquisa anterior, na qual se trabalhou o discurso do sujeito aluno da EJA. Nela, já foi possível compreender 
essa característica dos alunos mais velhos, sendo que o sujeito entrevistado não destacava o estudo em si, mas sim o acolhimento por intermédio da sociabilidade, que estar na EJA produz e significa para ele. Segundo Laraia (2013), para o analista de discurso, o dizer tem relação com o não dizer, o que deve ser acolhido e praticado na análise. Isso permite refletir que talvez, fora da EJA, o sujeito aluno não tenha esse acolhimento que diz ter na EJA. Como diz Ducrot (1972 apud ORLANDI, 2005, p. 82), "diferentes formas de nãodizer (implícito), o pressuposto e o subentendido, este autor vai separar aquilo que deriva propriamente da instância da linguagem (pressuposto) daquilo que se dá em contexto (subentendido)". Assim, o implícito se revela no dito desse aluno da EJA.

Retornando ao trabalho atual, a fala do professor faz compreender mais uma vez que muitos alunos, os mais velhos, ingressam na EJA em busca de novas amizades, mesmo afirmando que estão ali porque não tiveram oportunidade de estudar quando mais novos. Porém, esse discurso é somente um discurso já ouvido antes, é um já dito, e esse sujeito já ouviu dizer antes que existe uma escola para aquelas pessoas que não estudaram no "tempo certo". Estes alunos trazem consigo a bagagem da vida, um conhecimento imensurável, que é o conhecimento de vida, a sua experiência, sua vivência, que, como já foi dito anteriormente, aprendeu na "Escola da Vida", como ensinou Freire (1987).

Novamente em relação à $\mathrm{AD}$, deve-se entender que esse é um discurso fundador, isto é, um discurso já dito anteriormente por alguém que para se saber alguma coisa é preciso frequentar a escola, em outras palavras, é preciso buscar o saber institucionalizado, o saber pelo saber.

Em outro recorte da fala do sujeito professor D, ele diz: "Eles querem usar essa aprendizagem no trabalho deles". Entende-se nessa fala que o professor reproduz o discurso do sujeito aluno que, talvez ao ser questionado sobre o porquê de estar na EJA, tenha dito ao professor que estava ali por causa do trabalho. Como analista de discurso, pode-se intuir a presença da memória discursiva do sujeito aluno da EJA, que já ouviu dizer que, para possuir um bom trabalho, é preciso estudar. Pode-se compreender, nesse discurso do sujeito aluno e do sujeito professor, a perspectiva ideológica do sistema capitalista no qual se vive, pois o sujeito imagina-se mais valorizado pelo fato de estar produzindo.

Entende-se, através desse discurso que, mais uma vez, a escola é vista como local onde se deve preparar o sujeito para o mercado de trabalho, e o conteúdo aprendido na escola deve ser útil para o sujeito aluno ingressar no mundo da produção. Esse produzir não se baseia somente no fato mecânico da produção em si, mas sim como forma de ruptura, de independência desse sujeito, que, ao ser produtivo, vai ter como resultado uma maior independência financeira, a qual the possibilitará um deslocamento social.

Na sequência da entrevista, há outras formações discursivas do Professor W. O., 24 anos, há seis anos atuando na Educação de Jovens e Adultos.

Pesquisadora: Professor, o que a EJA significa para você como professor?

Professor: A EJA é muito importante, pois possibilita o retorno aos estudos àqueles que não tiveram oportunidade. No entanto, nos dias atuais está sendo uma forma de retirar dos turnos (matutino e vespertino) aqueles alunos acima da idade regular, que atrapalham o bom desenvolvimento dos mais novos. 
Os dizeres do professor contêm um discurso já produzido anteriormente por outras pessoas, como os próprios legisladores, quando da instituição da Lei das Diretrizes e Bases da Educação (LDB 5692/71), a qual regulamentava a EJA, e recomendava o atendimento de jovens e adultos. Conforme descrito no Art. n. 24, o ensino supletivo terá por finalidade:

a - Suprir a escolarização regular para os adolescentes e adultos que não a tenham seguido ou concluído na idade própria;

1 - Proporcionar, mediante repetida volta à escola, estudos de aperfeiçoamento ou atualização para os que tenham seguido o ensino regular no todo ou em parte (BRASIL, 1071, p. 1).

Pode-se entender o discurso do professor como um já dito, ou seja, esse dizer já foi ouvido anteriormente por ele. Como afirma Orlandi (2005), algo que já tenha sido dito, mas que, por qualquer motivo tenha sido esquecido, não deixa de ter um efeito sobre o dizer que se atualiza em uma nova formulação. Portanto, esse já dito anteriormente contribuiu para uma formação discursiva, dita nova, porém já cristalizada em sua memória discursiva. Com isso, nota-se que o sujeito professor retoma a sua memória quando diz que a EJA possibilita o retorno aos estudos àqueles que não tiveram oportunidade.

Prosseguindo com as análises, quando, por meio de seu discurso, o professor diz: “[...] nos dias atuais está sendo uma forma de retirar dos turnos (matutino e vespertino) aqueles alunos acima da idade regular, que atrapalham o bom desenvolvimento dos mais novos". Novamente, deve-se recordar a pesquisa anterior (LARAIA, 2013), quando já havia surgido essa formação discursiva, porém dita pelo próprio aluno da EJA, que reclamava que os alunos mais novos "atrapalhavam" os mais velhos. Essa formação discursiva era: "Como a gente volta a estudá na idade mais avançada, entendeu? Daí cê tem dificuldade pra estudá com jovens, entendeu? O jovem é mais barulhento”.

Este processo de migração do jovem com idade superior à regular acontece devido à grande incidência de reprovação que, no ensino regular, foi nomeada pelos órgãos governamentais competentes com "juvenilização da clientela da EJA" e é bastante difundida, pois foi o meio apropriado e encontrado para a continuidade do ensino desses alunos.

Na sequência da entrevista, aparecem outras formações discursivas da professora A. S., 56 anos, professora de língua portuguesa há 12 anos na EJA.

Pesquisadora: Professora, por que a senhora dá aulas na EJA?

Professora: Bom, eu poderia ter escolhido o ensino regular, mas eu escolhi EJA porque eu me considero com o perfil de EJA. Eu acho que língua portuguesa é muito bacana, tem que ter muita dedicação e é... Eu gosto de ver o aluno crescer, eu gosto que ele não fique parado no tempo. Então eu me considerei com o perfil de EJA.

Analisando o discurso da professora A. S., deve-se atentar quando questionada sobre o porquê de ela lecionar na EJA e então ela responde: "Eu poderia ter escolhido o ensino regular, mas eu escolhi EJA porque eu me considero com o perfil de EJA". Para 
as análises, sobre o recorte em que a professora diz: "Porque eu me considero com o perfil de EJA" é válido fazer algumas reflexões:

Qual será o perfil do professor da EJA? O que será que o professor da EJA precisa ter de diferente em relação ao professor do ensino regular? De acordo com a pedagogia de Freire (1987), observa-se que o professor da EJA, antes de se atentar à pedagogia, deve usar a andragogia, isto é, usar a arte ou ciência de orientar adultos a aprender, segundo a definição creditada a Malcolm Knowles, na década de 1970. O termo remete a um conceito de educação voltada para o adulto, em contraposição à pedagogia, que se refere à educação de crianças.

Pinto (1994, p. 72), em seu livro Sete Lições Sobre Educação de Adultos, afirma que:

A alfabetização de adultos é um processo pedagógico qualitativamente distinto do infantil [...] que o "equívoco" dos pedagogos que tratam igualmente adultos e crianças deve-se ao fato de eles não pensarem Educação no seu "contexto concreto" e que "Ihes falta a noção do caráter existencial da Educação [...] a diferença de procedimento pedagógico se origina na própria diferença no acervo cultural que possuem a criança e o adulto".

Com base na citação acima, é possível compreender, mais uma vez, o desinteresse do aluno da EJA, pois, se sabe que o adulto não quer e não aceita ser tratado como criança. O sujeito aluno da EJA quer ser visto como o sujeito que traz uma bagagem de vida e carrega consigo uma formação discursiva própria. Independente da formação discursiva das pessoas letradas.

Todo sujeito tem a sua formação discursiva, o que nos faz remeter a Orlandi (2009), quando afirma que as palavras não são só nossas. Elas significam pela história e pela língua, o que é dito em outro lugar também significa nas "nossas" palavras, ou seja, o sujeito diz, pensa que sabe o que diz, mas não tem controle sobre o modo pelo qual os sentidos se constituem nele.

Ainda nas análises, surge uma formação discursiva que, segundo Orlandi (2009), faz pensar que o sentido não existe em si, mas é determinado pelas posições ideológicas colocadas em jogo no processo sócio histórico no qual as palavras são produzidas. No seguinte recorte da fala da professora: "Porque eu me considero com o perfil de EJA", observa-se a posição ideológica da docente, que, diferentemente de outros professores, acredita que, para ser professora da EJA, é necessário ter um perfil diferente.

Para Pinto (1969, p. 67), "ensinar e aprender não podem dar-se fora da procura, fora da boniteza e da alegria", e Freire (1996) completa que a procura se dá porque não existe aprendizagem sem a pesquisa; a boniteza é pelo fato de que, para se aprender, necessita-se de um lugar arejado, limpo, iluminado e de uma comunidade de aprendizagem, e, finalmente a alegria é o resultado do prazer em aprender.

Por outro lado, no que diz respeito ao discurso e à posição ideológica da professora A. S.:

O discurso se constitui em seus sentidos porque aquilo que o sujeito diz se inscreve em uma formação discursiva e não outra para ter um sentido e não outro. Por aí podemos perceber que as palavras não têm um sentido nelas mesmo, elas derivam seus sentidos das formações discursivas em que inscrevem. As formações discursivas por sua vez, 
representam no discurso as formações ideológicas. Deste modo, os sentidos sempre são determinados ideologicamente. Não há sentido que não o seja (ORLANDI, 2009, p. 43).

Com base na citação acima, pode-se compreender que as formações discursivas não devem ser vistas como regiões estabilizadas e fechadas. Pelo contrário, elas são atravessadas por diferenças, contradições e movimentos. Movimentos esses que, para nosso entendimento, fazem a articulação das formações discursivas recentes com outras formações discursivas já existentes e que resultam em "novas" formações discursivas, que a autora chama de "regiões de confronto de sentidos".

Há outro dizer da professora que chama a atenção quando ela diz: "É de carinho, de dedicação, de ver aquela pessoa que não sabia quase nada, pode desenvolver um pouquinho mais a linguagem, pouquinho mais a escrita, é uma coisa de amor mesmo, né? Uma coisa de amor".

Novamente, é possível se deparar com a posição-sujeito da professora que não está somente preocupada que seu sujeito aluno aprenda a escrever e a ler, conforme exige a legislação para que ele se torne um sujeito letrado. Essa professora apresenta um discurso ideológico de amor ao próximo e demonstra saber que, para que o sujeito aprenda, ele precisa sentir-se amado, ele precisa sentir-se sujeito da situação em que está inserido. Segundo Laraia (2013), a ideologia intervém nas relações do sujeito com a língua e manifesta-se toda vez que se produz um discurso, pois ela é necessária para a constituição dos sujeitos e dos sentidos, assim como na relação do sujeito com a língua, dando oportunidade à formação do sentido para que, assim, haja sentido para o sujeito.

Diante disso, entende-se, então, que a linguagem funciona diferentemente para diferentes grupos, haja vista que diferentes materiais ideológicos configurados discursivamente participam do julgamento de uma situação (LARAIA, 2013).

Ao finalizar essas análises, pode-se compreender nesse objeto de estudo, isto é, no discurso dessa professora, o funcionamento da ideologia que está inscrita em seus discursos. Sabe-se que muitas questões ainda poderiam ser exploradas nessa pesquisa, mas o objetivo deste trabalho não é esgotar o assunto e espera-se que outros possam dar continuidade a este trabalho.

\section{Algumas considerações}

Buscou-se neste artigo compreender, por meio do interdiscurso, das formações discursivas e da memória dos nossos entrevistados, aqui nomeados de sujeito-professor, o sentido da EJA, para a realização profissional do sujeito-professor. Consideramos, para isso, que os sentidos estão sempre administrados e nunca soltos, como nos ensina Orlandi (2005), ou seja, ao atribuir sentidos, os sujeitos, ao entrarem em contato com o objeto simbólico, são convidados a interpretar e, ao interpretar, esses mesmos sujeitos retomam os sentidos que sempre já estiveram lá.

O professor, quando questionado sobre como ele vê o sujeito aluno da EJA, relata que o "estudante da EJA é um aluno especial", pelo fato de ele já contribuir para a sociedade com o seu trabalho. Compreende-se aí mais uma vez a noção de formação dos jovens e adultos para atender ao sistema capitalista e à mão de obra para o mercado de trabalho, portanto, mais uma vez nos aparece a ideologia capitalista engendrada no 
discurso do professor, que já traz consigo a formação discursiva a que a escola serve, para formar cidadão capaz de produzir para o Estado.

Não se pode omitir a necessidade, por parte de nossos governantes, de uma nova política de preparação e desenvolvimento de políticas públicas que realmente possam atender às reais necessidades dos sujeitos alunos da EJA, a fim de se poder pensar em uma sociedade mais justa e igualitária. Isso só acontecerá quando houver uma educação de qualidade que objetive a promoção e o desenvolvimento dos sujeitos, em outras palavras, quando a educação brasileira voltar seus olhos para o pensamento de Paulo Freire e deixar que os oprimidos o deixem de ser.

\section{REFERÊNCIAS}

AMADO, J. (Org.). Usos e abusos da história oral. 5. ed. Rio de Janeiro: FGV, 2002.

CAZARIN, E. A. Identificação e representação política: uma análise do discurso de Lula (1978-1998). 2004. 270 f. Tese (Doutorado em Estudos da Linguagem) - Instituto de Letras, Universidade Federal do Rio Grande do Sul, Porto Alegre, 2004. Disponível em: $<\underline{\text { http://www.lume.ufrgs.br/bitstream/handle/10183/5521/000427421.pdf? sequence }=1>}$. Acesso em: 03 mar. 2016.

DOMINGUES, A. S. A arte de falar: redescobrindo trajetórias e outras histórias da Colônia do Pulador - Anastácio-MS. Jundiaí: PACO, 2011.

FREIRE, P. Pedagogia da autonomia: saberes necessários à prática educativa. São Paulo: Paz e Terra, 1996. Pedagogia do oprimido. 17. ed. Rio de Janeiro: Paz e Terra, 1987.

GADOTTI, M. A educação contra a educação. Rio de Janeiro: Paz e Terra, 1979.

LARAIA, M. C. Os modos de (se) dizer sujeito-aprendiz: processos de identificação na educação de jovens e adultos de Pouso Alegre, MG. 2013. 103 f. Dissertação (Mestrado em Ciências da Linguagem) - Universidade do Vale do Sapucaí, Pouso Alegre, 2013. Disponível em: $<$ http://m.univas.edu.br/Repos_Biblioteca/00000000000000000022.pdf $>$. Acesso em: 12 mar. 2016.

ORLANDI, E. Gestos de leitura. Campinas: Unicamp, 1997.

História das idéias linguísticas: construção do saber metalinguístico e constituição da língua nacional. Campinas: Pontes, 2001.

2005.

. Análise de discurso: princípios e procedimentos. 6. ed. Campinas: Pontes, . As formas do silêncio. 6. ed. Campinas: UNICAMP, 2007.

. O que é linguística? 15. ed. São Paulo: Brasiliense, 2009.

. Análise de discurso: Michel Pêcheux. Textos selecionados. 2. ed. Campinas: Pontes, 2011.

PÊCHEUX, M. O discurso: estrutura ou acontecimento. Campinas: Pontes, 1991. 
PINHEIRO, S. R. S.; SILVA, A. P. A. Uma discussão sobre as políticas públicas em EJA. In: III ENNTEFH? Encontro Norte/Nordeste Trabalho, Educação e Formação Humana, Maceió, 2010.

PINTO, A. V. Ciência e existência: problemas filosóficos da pesquisa científica. Rio de Janeiro: Paz e Terra, 1969. Sete lições sobre educação de adultos. São Paulo: Cortez, 1994.

Recebido em: 22/09/2017

Aprovado em: 27/11/2017 